\title{
A Model Examining the Effect of Generative Learning on the Relationship between Diversification and Financial Performance
}

\author{
Tutku Seckin-Celik \\ Istanbul Medeniyet University, Istanbul
}

\begin{abstract}
Organizations are trying to attain and sustain competitive advantage in the highly competitive business world settings. It is argued that one of the strategies to achieve competitive advantage is to form learning organizations. Diversification strategies of organizations are important growth decisions managers need to make. In this paper, organizational learning, learning organization, fundamental diversification strategies and the link between learning and diversification in the literature were discussed shortly. Then, the link between them was revisited considering the literature with a schema. At last, a causal model was introduced. Model suggested that When a company decides to expand its operations by adding new products related to existing product line, with the aim of exploiting its existing knowledge base, this company can reach superior financial performance (financial performance means profitability) through generative learning. When a company decides to grow by adding a new product line irrelevant to existing product lines, with the aim of exploring new knowledge, then through generative learning, this company can introduce or develop new technologies in forms of new products/services, in other words make innovation. Unrelated diversification does not directly provide high financial performance. But gradually, as the innovation gain awareness, it brings in superior financial performance more than related diversification can bring in.
\end{abstract}

KEYWORDS: Organizational Learning, Diversification, Learning Organizations, Generative Learning, Adaptive Learning.

\section{ORGANIZATIONAL LEARNING AND LEARNING ORGANIZATIONS}

Organizations are trying to attain and sustain competitive advantage in the highly competitive business world settings. It is argued that one of the strategies to achieve competitive advantage is to form learning organizations. Before explaining these widely used interchangeable concepts, it is important to mention the difference between organizational learning and learning organizations, shortly. "Organizational learning is the distinctive behaviours that are characteristic of a learning organization and can be conceived as an entity. A Learning organization can be defined as an organization that implement organizational learning and can be conceived as procedural and behavioral terms" [1]. In other words, "organizational learning points to the process of knowledge creation in different levels of organizations and dissemination this learning/knowledge through the organization"; while learning organizations "indicates the structure because of organizational learning processes" [2].

In recent years, organizations have been trying to transform their organizational structures from their traditional roots to learning organizations. The reasons for this radical shift in organizations should not be rendered down to attaining and sustaining competitive advantage. There are some other reasons this extreme makeover within the organizations. Traditionally the most salient and somewhat more important factors of production was capital, however in today's world, people are what make the difference in an organizational setting, so labor becomes the most important factor of production. Although, employees are extremely important, organizations still use traditional management approaches and applications regarding the employees. Besides, knowledge and know/how are not included in the traditional factors of production, but contemporary sources also consider them as other factors of production together with the older four factors. Again, the difference is originated from people, or in other words 'intellectual labor'. Intense competition, demanding customers and ever- changing environment raise the importance of such factors in competitive advantage, and organizations have hard times due to these internal and external environmental demands. They must make fundamental changes to their social and physical organizational structures though their discomfort related to change. While considering their own experiences and others' practices, they are advised and led to new business models, structures, cultural settings, values, and philosophies to tap into organizational learning.

After looking at some of the root reasons behind organizational learning, we may evaluate some popular definitions of organizational 


\title{
International Journal of Current Science Research and Review
}

\author{
ISSN: 2581-8341
}

Volume 03 Issue 12 December 2020

DOI: 10.47191/ijcsrr/V3-i12-09, Impact Factor: 6.595

IJCSRR@ 2020

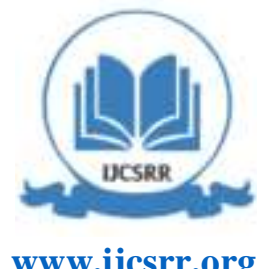

learning. The most salient figure in this topic is Senge. He defines learning organizations as "organizations where people continually expand their capacity to create the results, they truly desire, where new and expansive patterns of thinking are nurtured, where collective aspiration is set free, and where people are continually learning how to learn together" [3]. Another important researcher on OL, Garvin defines "a learning organization is an organization skilled at creating, acquiring, and transferring knowledge, and at modifying its behavior to reflect new knowledge and insights" and he further argues that learning organizations are good at five fundamental functions: "systematic problem solving, experimentation with new approaches (systematic searching for and testing of new knowledge), learning from their own experiences and past history, learning from the experiences and best practices of others, and transferring knowledge quickly and efficiently throughout the organization" [4].

Definitions of OL throughout the literature examined further seem abstract as the term OL itself. Also, most of them are criticized since they do not capture the essence at al. To better understand the importance of learning, it is convenient to look at the organization fitness model which was originally submitted by Beer in Building Organizational Fitness book. In order companies to be successful, they must fit their environments by aligning design, culture and leadership with their strategy, and they should also be able to learn and adapt to fit new circumstances (attain fitness). While organizations try to fit and achieve fitness, they face some obstacles such as resistance to change, old mental models, lack of communication, lack of involvement, unhealthy power, and politics. Organizational fitness model provides a framework to analyze the organization with a holistic approach and demonstrate the need of learning organizations [5].

There is a dotted outer layer in the model, and it shows us the organization exist in a competitive environment. Thus, the strategy requires a fit with the environment. First, organizational levers (leadership team, work system, management processes, human resource system, principles and culture, corporate context) must align. Then, through the capabilities of the organization (7C's: coordination, competence, commitment, communication, conflict management, creativity, capacity management) organizational goals (objectives and strategic tasks) can be achieved. Organizations are continuously in need of change due to ever-changing environmental conditions. At this point, learning loops are essential to provide feedbacks. Learning from fulfilment or nonfulfillment of objectives and strategic tasks nurture both capabilities and established organizational levers to revise and adapt to changes. Thus, learning is a continuous process throughout the organization.

Senge classifies organizations as to their learning approaches. Two overarching perspectives regarding organizational approaches are adaptive learning and generative learning [3]. As classical organizational theories suggest organizations need to adapt to their environmental demands in a reactive way with the aim of fitting in. So, when problems arise and something must be changed, organizations try to fix these problems without further investigating the root causes and systems underneath them. According to Senge, attempts to solve existing problems without questioning the underlying fundamental issues in the organizations is called as "adaptive learning". He argues that "adaptive approaches to learning originated from our tendencies to see the world as a combination of separated and unrelated forces", and "prevent us to make sense of the parts as a larger whole". Thus, it is about survival and coping with the environmental expectations, and such organizations cannot become learning organizations unless the underlying viewpoint is changed. Learning organizations require "generative learning" as well as adaptive learning. Senge indicates that generative learning requires new perspective and a holistic approach, and in that sense improves capacity to create something new in individuals within organizations. In a way, it is a continuous learning experience all around the organization [3].

Generative learning approach is more suitable for learning organizations and stipulates five disciplines. These five disciplines are systems thinking, personal mastery, mental models, building shared vision and team learning. Personal mastery is the discipline of clarifying and deepening the personal vision continually, focusing one's energy, developing patience, and seeing the realities in an objective way. Mental models indicate to be open-minded and clear one's mind against to the rooted assumptions, generalizations, or pictures and signs that influences one's viewpoint about the world and actions. Building shared vision suggests building a shared identity feeling which people make efforts and present their abilities in order organization to reach its goals, without pressuring people. Team learning refers to the efforts of thinking and working together as one by sharing knowledge and complement others' skills and to produce more than the capacity of one member. Systems thinking, seeing, and analyzing the whole not the fragments, is at the heart of these five disciplines and the discipline which holds all the other parts together [3].

In addition, organizational learning process should not be viewed as a one-way approach. March proposes a model of mutual learning reflecting the reciprocal nature of learning. "Organizational code" comprises the languages, beliefs and practices disseminated 


\section{International Journal of Current Science Research and Review}

ISSN: 2581-8341

Volume 03 Issue 12 December 2020

DOI: 10.47191/ijcsrr/V3-i12-09, Impact Factor: 6.595

IJCSRR@ 2020

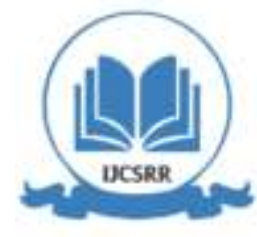

www.ijcsrr.org

through socialization processes in an organization. Members of the organizations learn and embrace organizational code but also organizations learn from its members and adapt the organizational code according to their member's beliefs. March also point out that there is a trade-off between the choice of exploitation and exploration of learning since they compete for scarce resources. Exploration includes things captured by terms such as search, variation, risk taking, experimentation, play, flexibility, discovery, innovation. Exploitation includes such things as refinement, choice, production, efficiency, selection, implementation, execution. Exploration means gaining new information and knowledge about possible alternatives and allocates resources to search for uncertain, risky alternatives. On the other hand, exploitation indicates using the existing information in best possible manner. Mutual learning model indicates that exploitation activities result in quick learning of organizational code, so organizations can quickly changes their practices to conform the environmental changes. On the other hand, exploration provides slow learning from the code, but produces much more diversity in beliefs in the long-run. Practices of organizational code in exploitation can be modified and conformed much more easily, so it removes interpersonal heterogeneity; while exploration requires great effort and time, and results in greater interpersonal heterogeneity [6].

\section{DIVERSIFICATION}

Diversification strategy is one of the most implemented corporate growth strategies. While a business operating in more than one sector is an indication that it applies a product diversification strategy, it is said that businesses operating in two or more geographic markets are implementing a market diversification strategy. These two strategies can be implemented simultaneously [7].

Diversification strategies of a firm also vary according to the relatedness of the new businesses with the existing businesses. Related diversification is termed when an organization expands its business in compliance with existing or similar product lines and markets through the common use of distribution channels, advertising, technological information, and so on. On the contrary, when an organization expands its business in unrelated new product lines and markets, it is termed as unrelated diversification. While implementing unrelated diversification, all business units are managed independently. There is also another type of diversification in between the other two types which is mentioned in the literature a lot: related-linked diversification. Related-linked diversification helps companies to share their core skills such as know-how, human resources, R\&D expenditures, and advertising while business units are still independent of each other principally [8], [9].

The decision of diversification depends on the nature of available excess resources in the light of Resource-Based Approach. Some of the resources can be used to produce more than one product and this ability indicates a resource's flexibility. Increasing flexibility of a resource, also increase the chance of more unrelated diversification. So, excess physical resources (plant, equipment) and intangible assets (brand name, technology, advertising) are expected to lead to related diversification since they are more rigid and useful in markets close to each other, while excess financial resources are expected to favor both related and unrelated diversification, since money can be used for all purposes [10].

\section{THE LINK BETWEEN ORGANIZATIONAL LEARNING AND DIVERSIFICATION}

Following March's approach to organizational learning, Bing and Quian classified organizational learning into exploration and exploitation of knowledge and search for the effect of organizational learning on diversification and enterprise performance. The effect of organizational learning on firm performance has been widely investigated and confirmed. They infer from the existing literature that the attitude of exploration makes firms tend to discover new markets and create new products through unrelated diversification, and in the short run, it is not possible to realize a significant financial improvement. On the contrary, the attitude of exploitation prescribes firms to focus and improve their existing products and procure them to improve financial performance substantially. They also expect diversification to increase new product performance, while specialization (or not diversifying) to increase overall financial performance. Since, diversification, especially unrelated diversification, requires huge amount of capital, they further expect a relationship with capital structure and diversification decision [11].

With the help of questionnaires, they confirm some of their hypothesis. As expected, organizational learning significantly effects both diversification decision and capital structure. They found that explorative learning has a direct effect on diversification, on the contrary, exploitation prevents diversification. Diversification choice, whether exploitative or explorative nature, does not depend on the capital structure of the firm. Also, diversification, indirectly affects the overall financial performance through affecting new 


\section{International Journal of Current Science Research and Review}

ISSN: 2581-8341

Volume 03 Issue 12 December 2020

DOI: 10.47191/ijcsrr/V3-i12-09, Impact Factor: 6.595

IJCSRR @ 2020

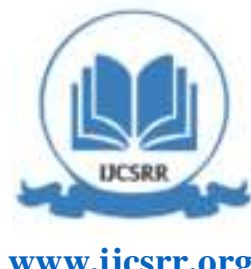

www.ijcsrr.org

product performance. Then they modified the model and the relationship between variables were updated as explained before.

In another study based on March's adaptation of exploitation and exploration terms in organizational learning, these two approaches of learning were conceived as related and unrelated diversification. Attempts of one company to optimize their existing resources through related diversification were viewed as exploitation; while attempts of one company to improve competitive advantage through unrelated diversification as exploration activities. Related diversification led to improvements in performance only in the short run, while unrelated diversification will be successful in the long run. Thus, they suggest that there must be a balance between related and unrelated diversification for a firm to sustain their competitive position due to both types have their own strengths and weaknesses. They also claim that the relationship between diversification and performance is not linear, as is commonly represented. They developed a Cobb-Douglass function model to truly assess the contribution of related and unrelated diversification on firm performance. According to their model, the marginal contribution of diversification achieves its highest value when related and unrelated diversification are held to be equal [12].

Lau suggested diversification strategies to be examined in terms of their coordination and control mechanisms, corporate managers' ways of doing business, and organizational learning climates (learning capacity and learning needs). Different types of diversification strategies require different types of management strategies and organizational systems to sustain competitive advantage [9].

Coordination is centralized at the head office, there is a significant intergration among interdivision, control system is based on both subjective and objective non-financial criteris, incentive system is based on corporate profitability, managers are cooperative and must take substantial risks in related diversification. In such a setting, internal stakeholders have to learn the knowledge that include shared corporate management vision and mission, shared management philosophy, and shared management skills to build a collaborative mind set. Also, a participative learning system, in which members' contributions are appreciated in a cooperative work setting, should also be implemented as a supporting system.

On the other hand, in unrelated diversification, decisions are decentralized to divisions, there is no integration among division, control systems are based on objective financial criteria, incentive system is based on divisional profitability, managers are competitive and short-run focus. The only knowledge to share is financial knowledge. And since unrelated diversification is established as an independent unit and mostly implemented through acquisitions, a buraucratic learning system, where guidelines, procedures, regulations are strongly communicated, is recommended.

When related-linked diversification is the chosen strategy, decisions are mostly centralized, there is some degree of integration among interdivisions, control system are based mainly on financial controls, incentive system is based on corporate profitability, managers are transferred frequently, and their mind sets focus on short-run. Managers slog to balance between cooperative and competitive mind set, thus a formal learning system, in between bureaucratic and participative learning systems, emphasizes systematic planning, control, information management is suitable for related-linked diversification.

Tidd and Saurins classify motives for diversification through learning approaches as leveraging and learning. Leveraging attempts indicates exploiting existing knowledge to reach new technologies and markets, while learning attempts concern for developing new knowledge and competencies. They build a factorial design which demonstrate appropriate organizational structures and management processes based on the learning approach [13].

When the importance of learning new knowledge is low and leveraging existing knowledge is high, then direct integration is the appropriate structure. Direct integration of new business with existing business as an additional mainstream activity indicates sharing common resources throughout the organization and requires a complete cultural alignment. Through the transformation process, both new skills (in some degree) and existing latent skills would emerge. When the importance of both learning new knowledge and leveraging existing knowledge is high, when the requested change is beyond current products and markets, a separate corporate venturing unit or department is suitable. When the importance of learning new knowledge is high and leveraging existing knowledge is low, startup venture wholly owned by the corporation is recommended. There is a strong need for control, but unit should be isolated from the short term pressures of the mainstream businesses. Although some of the key personal of center can be staffed in this dedicated venture unit, unit primarily should be controlled on its own. When both learning or leveraging has low importance, some units/activities that are not critical to mainstream business or have low strategic importance for the core business can be 


\section{International Journal of Current Science Research and Review}

ISSN: 2581-8341

Volume 03 Issue 12 December 2020

DOI: 10.47191/ijcsrr/V3-i12-09, Impact Factor: 6.595

IJCSRR@ 2020

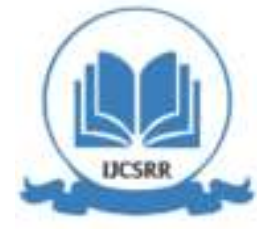

www.ijcsrr.org

spinned- off by forming independent business units. The degree and extent of administrative control over the new business unit is determined depending on the ownership degree of organization.

\section{ORGANIZATIONAL LEARNING AND DIVERSIFICATION REVISITED}

Based on the literature on organizational learning and diversification, the following framework can be proposed as a guideline. Although there is a tendency to assume individual learning and organizational learning as separate terms, organizations formed by their members, so it is convenient to claim that organizational learning starts with individual learning [14]. Through the realization of five disciplines, Senge suggested individual learning leads to generative learning. Adaptive learning, the first phase of organizational learning, is shown with the dashed line due to lack of these principles [3]. Organizational learning then could be classified according to the purpose of using organizational knowledge as exploitation and exploration. Not all learning organizations have to choose exploration all the time, they may choose exploitation for quick profit returns. If they want to exploit their existing knowledge, they choose related diversification or related-linked diversification strategies; if they want to explore new alternatives, they choose unrelated diversification or related-linked diversification. The decision of what kind of diversification is selected also depends on the nature of the excess resources. Excess physical resources promote related diversification; excess intangible assets promote related-linked diversification, while excess financial resources incite all types of diversification including unrelated diversification.

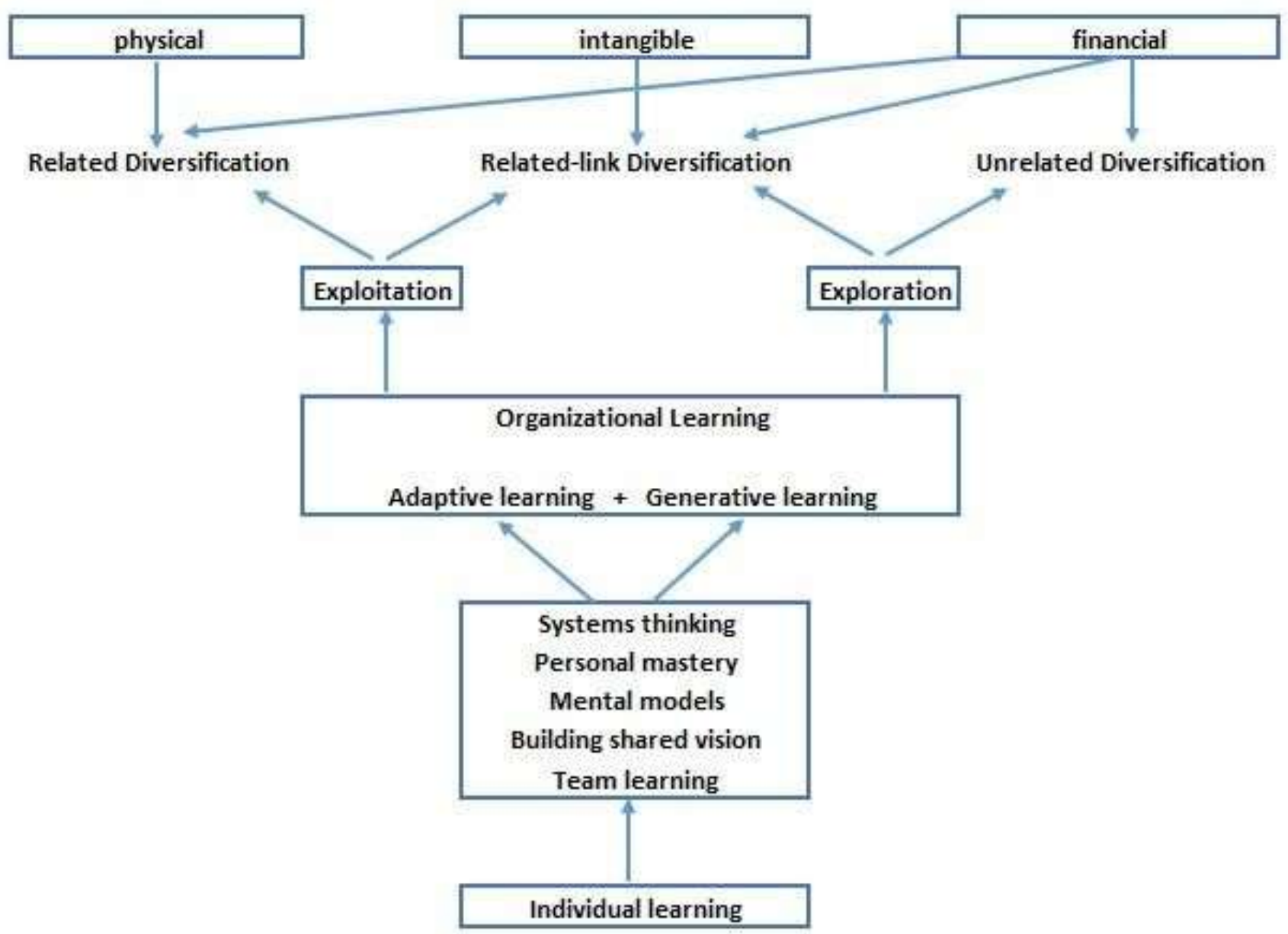

Figure 1: A framework for diversification and organizational learning 


\section{International Journal of Current Science Research and Review}

ISSN: 2581-8341

Volume 03 Issue 12 December 2020

DOI: 10.47191/ijcsrr/V3-i12-09, Impact Factor: 6.595

IJCSRR@ 2020

Www.ijcsrr.org

\section{CAUSAL MODEL}

Depending on the inferences from the literature examined, a model has emerged. Diversification mentioned in the model is product diversification strategy. When a company decides to expand its operations by adding new products related to existing product line, with the aim of exploiting its existing knowledge base, this company can reach superior financial performance (financial performance means profitability) through generative learning.

When a company decides to grow by adding a new product line irrelevant to existing product lines, with the aim of exploring new knowledge, then through generative learning, this company can introduce or develop new technologies in forms of new products/services, in other words make innovation. Unrelated diversification does not directly provide high financial performance. But gradually, as the innovation gain awareness, it brings in superior financial performance more than related diversification can bring in.

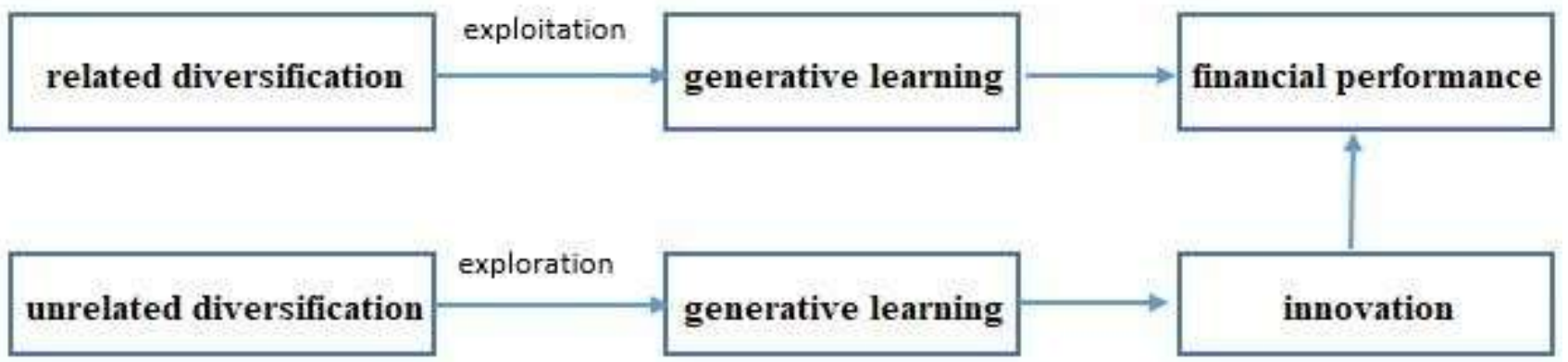

Figure 2: Proposed Model

\section{REFERENCES}

1. Harvey, C., \& Denton, J. (1999). To come of age: the antecedents of organizational learning. Journal of Management Studies, 36(7), 897-918.

2. Thomas, K., \& Allen, S. (2006). The learning organization: a meta-analysis of themes in literature. The Learning Organization, 13(2), 123-139.

3. Senge, P. M. (1994) The Fifth Discipline: The Art and Practice of the Learning Organization, Bantam Doubleday Dell Publishing, New York.

4. Garvin, D. A. (1993). Building a learning organization. Harvard Business Review, July-August, 78-91.

5. Beer, M., Voelpel, S. C., Leibold, M., \& Tekie, E. B. (2005). Strategic management as organizational learning: developing fit and alignment through a disciplined process. Long Range Planning, 38(5), 445-465.

6. March, J. G. (1991). Exploration and exploitation in organizational learning. Organization science, 2(1), 71-87.

7. Barney, J. B., \& Hesterly, W. S. (2008). Strategic management and competitive advantage: concepts. Pearson/Prentice Hall.

8. Chatterjee, S., \& Wernerfelt, B. (1991). The link between resources and type of diversification: theory and evidence. Strategic Management Journal, 12(1), 33-48.

9. Lau, C. M. (1993). Diversify with care: diversification strategies and organization development. International Journal of Organizational Analysis, 1(1), 55-72.

10. Chatterjee, S., \& Wernerfelt, B. (August, 1988). "Related or Unrelated Diversification: A Resource Based Approach.” In Academy of Management Proceedings (Vol. 1988, No. 1, pp. 7- 11). Academy of Management.

11. Bing, C., \& Quian, L. (August, 2010). "The Research on the Effect of Organizational Learning on Diversification and Capital Structure Strategy in Small and Medium-Sized Enterprises: An Empirical Research Based on Structural Equation Modeling." International Conference on Management and Service Science (MASS). (Available at http://ieeexplore.ieee.org/xpl/articleDetails.jsp?arnumber=5576173, Access Date: 11.12.2020). 


\section{International Journal of Current Science Research and Review}

ISSN: 2581-8341

Volume 03 Issue 12 December 2020

DOI: 10.47191/ijcsrr/V3-i12-09, Impact Factor: 6.595

IJCSRR@ 2020

www.ijcsrr.org

12. Dangol, R., Sharma, S. K., \& Ahmed, N. (2008). Diversification-performance: analyzing the relationship from the learning school perspective. Proceedings of Annual Decision Sciences Institute Conference, 3281-3286.

13. Tidd, J., \& Taurins, S. (1999). Learn or leverage? Strategic diversification and organizational learning through corporate ventures. Creativity and Innovation Management, 8(2), 122-129.

14. Kim, D. H. (1993). The link between individual and organizational learning. Sloan Management Review, Fall, 37-50

Cite this Article: Tutku Seckin-Celik (2020). A Model Examining the Effect of Generative Learning on the Relationship between Diversification and Financial Performance. International Journal of Current Science Research and Review, 3(12), 264-270 